\title{
Anti-Obesity Properties of Black Pepper (Piper nigrum): Completing Puzzle using Computational Analysis
}

\author{
Nurun Nafi'atul Lailiyah ${ }^{1}$, Mutiara Dwirosita Ibrahim ${ }^{1}$, Chunafa Ayu Fitriani ${ }^{1}$, Feri Eko Hermanto ${ }^{1}$ \\ ${ }^{1}$ Department of Biology, Faculty of Mathematics and Natural Sciences, Brawijaya University, Jalan Veteran, Malang, East Java, \\ Indonesia, 65145
}

Submission: 01 June 2021; Revised: 12 October 2021; Accepted: 17 October 2021

*Corresponding author: Nurun Nafi'atul Lailiyah; e-mail: courage.nurun@gmail.com; tel.:-

\begin{abstract}
Pepper (Piper nigrum) is one of the most common spices found in almost every food. Current knowledge informed that pepper regulates physiological activity in obesity. However, the exact mechanism is still poorly understood. This study determined the potential of piperine and piperidine as major compounds in pepper as GHSRGhrelin inhibitors due to over-activity of Ghrelin as appetite hormone in obesity. Molecular docking was performed to simulate the binding pattern of piperine and piperidine as GHSR-Ghrelin antagonist. The result showed that piperidine has a lower potential as GHSR-Ghrelin antagonist than piperine based on binding energy calculation and amino acid interaction. Further, piperine binding to GHSR could shift the Ghrelin binding site to the GHSR. In conclusion, piperine may act as an inhibitor of GHSR-Ghrelin interaction to prevent appetite behavior resulting in bodyweight loss in obesity.
\end{abstract}

Keywords: Ghrelin, GHSR, obesity, piperidine, piperine

\section{INTRODUCTION}

Obesity included in a serious health concern worldwide. with the number of prevalence was increasing year by year, obesity becomes one of dangerous health risk among modern civilizations. Obesity have bigger risk to develop another health problem, particularly related to cardiovascular diseases (CVD) [1]. Moreover, obese patients also have high susceptibility to COVID-19 and increase the probability to death [2]. Interestingly, countries with mid-to-high income have more obesity cases compared to the underdeveloped countries globally [3]. On the other hand, people with high annual income are also more susceptible to obesity, suggesting a socio-economic status also played a role in developing this metabolic disease $[4,5]$.

Since obesity is included as a metabolic disease, controlling food consumption has a significant role in regulating obesity status and development [6]. Thus, physiological regulation related to appetite also become a promising site to counteract obesity development [7]. One appetite hormone, known as Ghrelin, has a significant role in obesity treatment [8, 9]. Ghrelin is overproduction in obese conditions compared to the normal [10], suggesting a physiological target to decrease the obesity prevalence among civilizations $[8,11]$. Hence, this study focused in Ghrelin as a target to prevent the obesity progression.

Controlling bodyweight using food regulation has a key role in suppressing obesity status $[12,13]$. A familiar and frequently used food spices, Pepper (Piper nigrum), known to has some physiological benefit to improve human health [14]. Among two pepper types, black pepper is the most used spices in numerous foods due to its strong taste. The strong taste of black pepper is due to the presence of piperin and piperidine as alkaloid [15]. Those compounds also have numerous biological activity, such as antimicrobial action, immunomodulatory, antioxidant, antitumor, antimetastatic, antidepressant and many other activities [16-18], suggesting a promising role as Ghrelin inhibitor for obesity treatment. Therefore, this study aimed to investigate possible mechanism of piperine and piperidine as Ghrelin inhibitor to suppress the development of obesity.

\section{RESEARCH METHODS}

\section{Data Mining of Compound and Protein Structures}

Piperine (CID: 638024) and piperidine (CID: 8082) were retrieved from PubChem database and used as the ligands. The protein were retrieved from RCSB PDB with PDB ID 6KO5 and $6 \mathrm{H} 3 \mathrm{E}$ for Growth Hormone Secretagogue Receptor (GHSR) as receptor for Ghrelin and Ghrelin itself, respectively. Protein's structure was prepared using Biovia Discovery Studio version 16 (Dassault Systemes BIOVIA, 2015) to remove attached ligands and water molecule. Ligands were prepared using OpenBabel integrated in PyRx $8.0[19,20]$ to minimize the energy prior to docking process. 


\section{Molecular Docking and Analysis}

Protein-ligands docking was simulated using AutoDock Vina in PyRx software with maximum grid setting as performed in the previous study [21], while protein-protein interactions were docked by the HDOCK server [22]. Structure visualization and interacting residues then analyzed using Biovia Discovery Studio. Binding energy from docking process and amino acid residue interaction were used as consideration to assess the inhibitory activity of piperine and piperidine.

\section{RESULTS AND DISCUSSIONS}

Piperidine has higher binding energy than piperine (Table 1). Also, the binding of the ligands to the GHSR showed lower binding energy than piperine or piperidine binding to Ghrelin (Table 1). This result suggests that piperine or piperidine acted more efficiently as GHSR inhibitor rather than Ghrelin. Interaction of piperidine-Ghrelin involved two residues, GLU:8 and PHE: 4 with hydrogen and hydrophobic bonds (Figure 3). Previous research, revealed that GLU:8 may be a low percentage of the $\alpha$-helix region [32], and PHE:4 is an active core neither displaces ghrelin from its receptor nor stimulates growth hormone release [33]. According to binding energy calculation and amino acid interaction, piperine provided a potential to be an inhibitor of GHSR-Ghrelin interaction. Therefore, piperine was directed into further analysis related to its inhibitory mechanism.

Table 1. The binding energy of analyzed ligands interacted with targeted proteins

\begin{tabular}{lcc}
\hline \multirow{2}{*}{ Macromolecule } & \multicolumn{2}{c}{ Binding energy $(\mathbf{k c a l} / \mathbf{m o l})$} \\
\cline { 2 - 3 } & Piperidine & Piperine \\
\hline Ghrellin & -2.5 & -5.7 \\
GHSR & -4.3 & -8.2 \\
\hline
\end{tabular}

Amino acid interaction revealed that piperine has more interaction residue with the ligand (GHSR) compared to the Ghrelin (Figure 1). This data was in line with the binding energy measurement which piperine-GHSR complex has less energy necessity to form a complex compared to piperine-Ghrelin (Table 1). Interaction of piperine-Ghrelin involved only two residues in active site of Ghrelin-GHSR complex, i.e. GLN:10 and GLU:17 with hydrogen bond and van der waals interaction, respectively. Conversely, piperine could interact with GHSR through several amino acid residues using several chemistry interactions such as hydrogen bond, electrostatics, and van der waals (Figure 1). Hydrogen bond serves an important function in protein folding, as the facilitators of the protein bond with ligan, and the enzymatic catalysis [23]. However, electrostatics and other chemistry interaction also play role in protein-ligand structure stability $[24,25]$. So that, interaction of piperine with GHSR was preferable to achieve inhibitory mechanism.

To understand the influence of piperine binding to GHSR-Ghrelin interaction, proteinprotein docking was performed using piperinebounded GHSR (GHSR+piperine) with Ghrelin as well as GHSR with piperine-bounded Ghrelin (Ghrelin+piperine) (Figure 2). Structural visualization showed that piperine binding to GHSR was more effective to alter binding motif of GHSR-Ghrelin (Figure 2C) compared to the binding of piperine with Ghrelin (Figure 2B). Analysis of amino acid interaction also strengthen the inhibitory mechanism of piperine to the GHSR-Ghrelin signaling with different amino acid involvement of (Ghrelin+piperine)-GHSR compared to the Ghrelin-(piperine+GHSR) complex (Table 2). This result emphasized the antagonism properties of piperine through the binding into GHSR to prevent GHSR-Ghrelin complex formation and inhibit appetite behavior, reduce the intake of glucose and lipid in the body, so that weight loss minimize obesity.

Development of GHSR antagonist gains an insight to reduce bodyweight. Previous study revealed that GHSR antagonist succeed to reduce food intake and bodyweight [26, 27]. Several bioactive compounds extracted from natural sources also have beneficial impact in reducing bodyweight, particularly related to obesity [27, 28]. Black pepper-contained diet could suppress the appetite [29]. Besides, piperine as major alkaloid in black pepper also induces lipidlowering effect and body weigh shrinkage [30, 31]. With current result using computational analysis, anti-obesity mechanism of piperine has assembled successfully. 


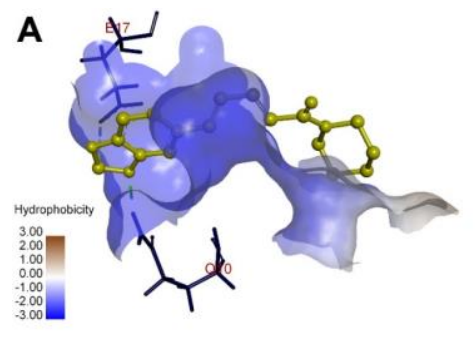

C

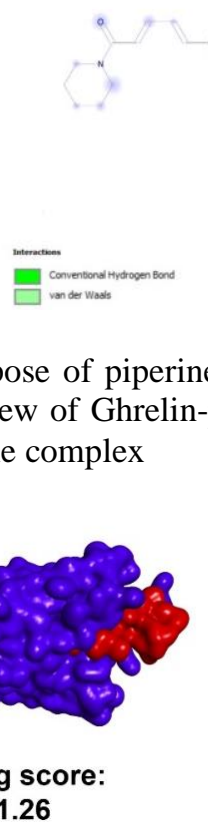

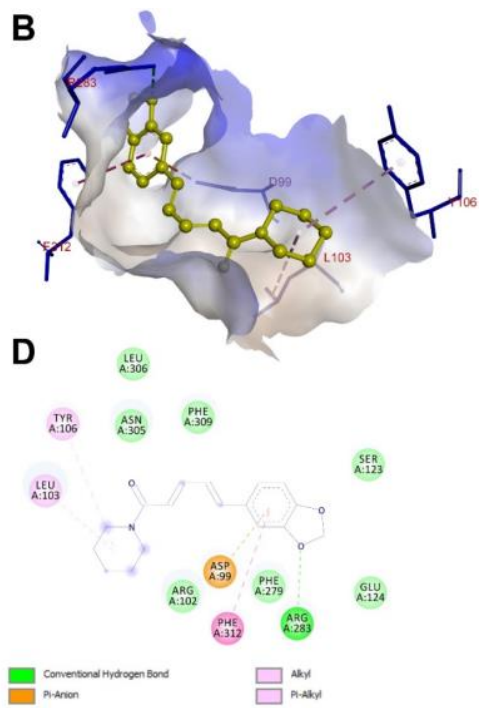

Figure 1. The binding pose of piperine compound with GHSR and Ghrelin, $(A, C)$ interactions sites, hydrophobicity level \& 2D view of Ghrelin-piperine complex, (B,D) interactions sites, hydrophobicity level \& 2D view of GHSR-piperine complex
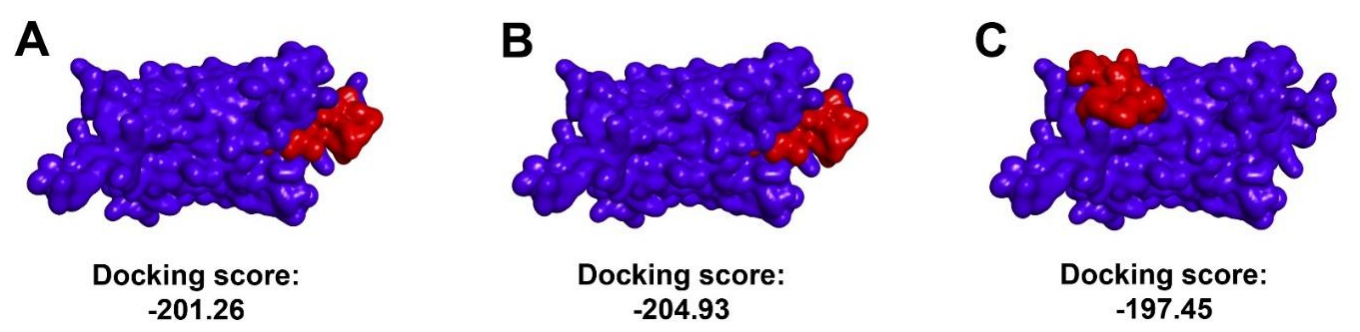

Figure 2. Structural orientation of ligand protein complex. Ghrelin-GHSR (A), [Ghrelin + piperine]-GHSR (B), Ghrelin-[piperine + GHSR] (C).

Table 2. Interacting residues in Ghrelin and GHSR with piperine and piperidine compound

\begin{tabular}{|c|c|c|c|c|c|}
\hline \multirow{2}{*}{ Complex } & \multicolumn{2}{|c|}{ Interacted residue } & \multirow{2}{*}{ Distance } & \multirow{2}{*}{ Category } & \multirow{2}{*}{ Types } \\
\hline & From & To & & & \\
\hline \multirow[t]{12}{*}{ GHSR-Piperine } & A:GLY1:N & A:GLU124:OE2 & 3.30 & \multicolumn{2}{|c|}{ Hydrogen Bond;ElectrostaticSalt Bridge } \\
\hline & \multicolumn{2}{|c|}{ A:ARG102:NH2A:SER2:OG } & 3.02 & Hydrogen Bond & Conventional Hydrogen Bond \\
\hline & \multicolumn{2}{|c|}{ A:ARG283:NH2A:SER2:O } & 2.29 & Hydrogen Bond & Conventional Hydrogen Bond \\
\hline & A:PHE286:N & A:SER6:O & 3.09 & Hydrogen Bond & Conventional Hydrogen Bond \\
\hline & A:SER289:OG & A:HIS9:O & 2.85 & Hydrogen Bond & Conventional Hydrogen Bond \\
\hline & A:GLY1:N & A:THR127:OG1 & 3.05 & Hydrogen Bond & Conventional Hydrogen Bond \\
\hline & A:ARG11:NE & A:TYR106:OH & 2.67 & Hydrogen Bond & Conventional Hydrogen Bond \\
\hline & A:ARG11:NH2 & A:TYR106 & 3.89 & \multicolumn{2}{|c|}{ Hydrogen Bond;ElectrostaticPi-CationDonor Hydrogen Bond } \\
\hline & A:PHE286 & A:PHE4 & 5.76 & Hydrophobic & Pi-Pi T-shaped \\
\hline & A:ARG199 & A:ARG11 & 4.02 & Hydrophobic & Alkyl \\
\hline & A:PRO7 & A:LEU285 & 4.16 & Hydrophobic & Alkyl \\
\hline & A:PHE279 & A:LEU5 & 5.49 & Hydrophobic & Pi-Alkyl \\
\hline \multirow[t]{8}{*}{ [Ghrellin+Piperine]-GHSR } & A:GLY1:N & A:GLU124:OE2 & 3.35 & Electrostatic & Attractive Charge \\
\hline & \multicolumn{2}{|c|}{ A:ARG102:NH2A:SER2:OG } & 3.27 & Hydrogen Bond & Conventional Hydrogen Bond \\
\hline & \multicolumn{2}{|c|}{ A:ARG283:NH2A:SER2:O } & 2.29 & Hydrogen Bond & Conventional Hydrogen Bond \\
\hline & A:SER289:OG & A:HIS9:O & 2.78 & Hydrogen Bond & Conventional Hydrogen Bond \\
\hline & A:GLY1:N & A:THR127:OG1 & 2.91 & Hydrogen Bond & Conventional Hydrogen Bond \\
\hline & A:ARG11:NE & A:TYR106:OH & 2.60 & Hydrogen Bond & Conventional Hydrogen Bond \\
\hline & A:SER2:CA & A:ASP99:OD2 & 3.74 & Hydrogen Bond & Carbon Hydrogen Bond \\
\hline & A:ARG11:NH2 & A:TYR106 & 3.76 & Electrostatic & Pi-Cation \\
\hline
\end{tabular}


Nurun NL, Mutiara DI, Chunafa AF, Feri EH - Anti-Obesity Properties of Black Pepper (Piper nigrum)

\begin{tabular}{|c|c|c|c|c|c|}
\hline \multirow{3}{*}{ Complex } & \multicolumn{2}{|c|}{ Interacted residue } & \multirow{2}{*}{ Distance } & \multirow{2}{*}{ Category } & \multirow{2}{*}{ Types } \\
\hline & From & To & & & \\
\hline & A:PHE286 & A:PHE4 & 5.97 & Hydrophobic & Pi-Pi T-shaped \\
\hline \multirow{10}{*}{ Ghrellin-[GHSR+Piperine] } & \multicolumn{2}{|c|}{ A:ARG237:NH2A:GLU17:OE2 } & 4.79 & Electrostatic & Attractive Charge \\
\hline & \multicolumn{2}{|c|}{ A:ARG159:NH1A:ASP3:O } & 3.13 & Hydrogen Bond & Conventional Hydrogen Bond \\
\hline & \multicolumn{2}{|c|}{ A:ARG159:NH1A:PHE4:O } & 3.19 & Hydrogen Bond & Conventional Hydrogen Bond \\
\hline & A:HIS9:CD2 & A:TYR142:OH & 2.71 & Hydrogen Bond & Carbon Hydrogen Bond \\
\hline & A:TYR142:OH & A:HIS9 & 3.24 & Hydrogen Bond & Pi-Donor Hydrogen Bond \\
\hline & A:HIS9 & A:TYR142 & 5.21 & Hydrophobic & Pi-Pi T-shaped \\
\hline & A:VAL153 & A:LEU5 & 5.45 & Hydrophobic & Alkyl \\
\hline & A:CYS227 & A:ARG11 & 4.64 & Hydrophobic & Alkyl \\
\hline & A:ARG15 & A:LEU234 & 4.20 & Hydrophobic & Alkyl \\
\hline & A:HIS9 & A:LEU234 & 5.19 & Hydrophobic & Pi-Alkyl \\
\hline \multirow[t]{2}{*}{ GHSR-Piperidine } & N:UNK1:C & A:VAL68 & 5.12 & Hydrophobic & Alkyl \\
\hline & A:TYR330 & $\mathrm{N}: \mathrm{UNK} 1: \mathrm{C}$ & 5.13 & Hydrophobic & Alkyl \\
\hline \multirow[t]{2}{*}{ Ghrelin-Piperidine } & $\mathrm{N}: \mathrm{UNK}: 1: \mathrm{H}$ & A:GLU:8:O & 2.18 & Hydrogen Bond & Conventional Hydrogen bond \\
\hline & A:PHE4 & $\mathrm{N}: U N K 1: \mathrm{C}$ & 4.82 & Hydrophobic & Pi-Alkyl \\
\hline
\end{tabular}
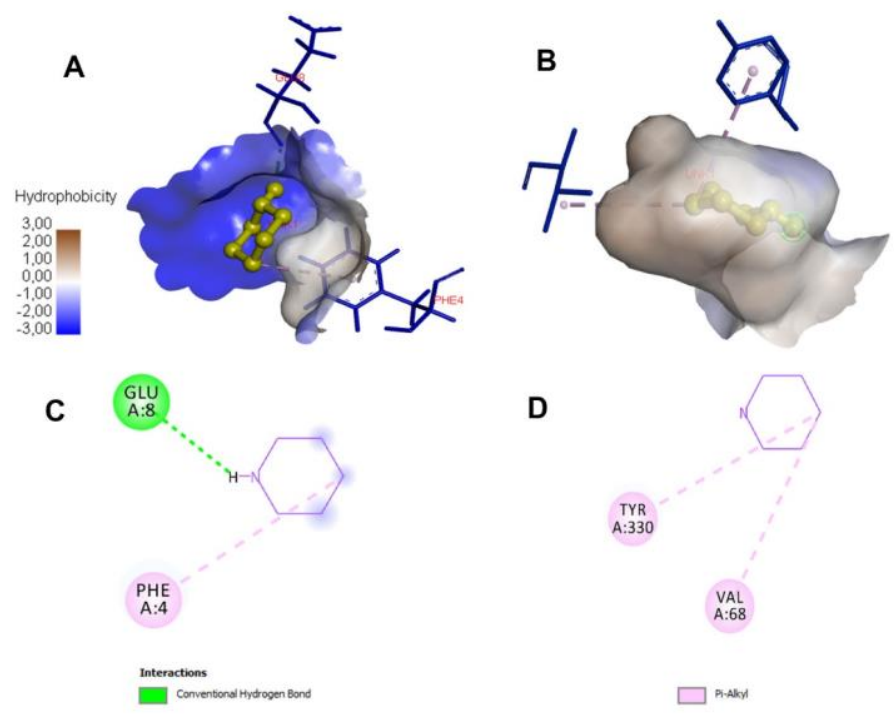

D

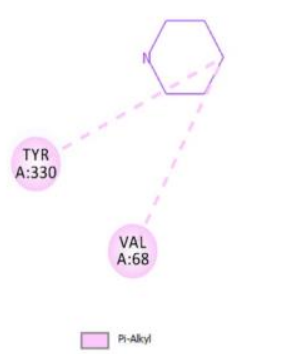

Figure 3. The binding pose of piperidine compound with GHSR and Ghrelin, (A,C) interactions sites, hydrophobicity level \& 2D view of Ghrelin-piperidine complex, (B,D) interactions sites, hydrophobicity level \& $2 \mathrm{D}$ view of GHSR-piperidine complex

\section{CONCLUSION}

Anti-obesity of piperine may achieve through inhibition of GHSR as the receptor of appetite hormone Ghrelin. Accordingly, piperine has a good potential to be a GHSR antagonist for anti-obesity treatment.

\section{ACKNOWLEDGEMENT}

We would like to thank to all of our bioinformatics lecturers, Prof. Fatchiyah, M.Kes., Ph.D., Prof. Widodo, Ph.D.Med.Sc., Nia Kurniawan, S.Si, MP, D.Sc., all of our laboratory assistants who have provided knowledge, direction and guidance for us in this research.

\section{REFERENCES}

[1]. Powell-Wiley, T.M., Poirier, P., Burke, L.E., Després, J.P., Gordon-Larsen, P., Lavie, C.J., Lear, S.A., Ndumele, C.E., Neeland, I.J., Sanders, P., and St-Onge, M.P., 2021, Obesity and cardiovascular disease: a scientific statement from the American Heart Association, Circulation, 143(21), e984e1010.

[2]. Popkin, B.M., Du, S., Green, W.D., Beck, M.A., Algaith, T., Herbst, C.H., Alsukait, R.F., Alluhidan, M., Alazemi, N., and Shekar, M., 2020, Individuals with obesity and COVID-19: a global perspective on the 
epidemiology and biological relationships, Obesity Reviews, 21(11), 1-17.

[3]. Yosuke, I., Bo, Q., Jennifer, P., Sokol, R., and Gordon-Larsen, P., 2018, Epidemiology of obesity in adults: latest trends, Current Obesity Reports, 7(4), 276-288.

[4]. Dinsa, G.D., Goryakin, Y., Fumagalli E., and Suhrcke M., 2012, Obesity and socioeconomic status in developing countries: a systematic review, Obesity Reviews, 13(11), 1067-1079.

[5]. Monteiro, C.A., Moura, E.C., Conde, W.L., and Popkin, B.M., 2004, Socioeconomic status and obesity in adult populations of developing countries: a review, Bull World Health Organ, 82(12), 940-946.

[6]. Kim, G.W., Lin, J.E., Valentino, M.A., Colon-Gonzalez, F., and Waldman, S.A., 2011, Regulation of appetite to treat obesity, Expert Reviews Clinical Pharmacology, 4(2), 243-259.

[7]. Miller, G.D., 2017, Appetite regulation: hormones, peptides, and neurotransmitters and their role in obesity, American Journal of Lifestyle Medicine, 13(6), 586-601.

[8]. Colldén G., Tschöp M.H., and Müller, T.D., 2017, Therapeutic potential of targeting the ghrelin pathway. International Journal of Molecular Sciences, 18(4), 798.

[9]. Álvarez-Castro, P., Pena, L., and Cordido, F., 2013, Ghrelin in obesity, physiological and pharmacological considerations, Mini Reviews in Medicinal Chemistry, 13(4), 541552.

[10]. Makris, C.M., Alexandrou, A., Papatsoutsos, E.G., Malietzis, G., Tsilimigras, D.I., Guerron, A.D., and Moris, D., 2017, Ghrelin and obesity: identifying gaps and dispelling myths. A reappraisal. In Vivo, 31(6), 10471050.

[11]. Horvath, T.L., Castañeda, T., TangChristensen M., Pagotto, U., and Tschöp, M.H., 2003, Ghrelin as a potential antiobesity target, Current Pharmaceutical Design, 9(17), 1383-1395.

[12]. Zhang, Q., Liu, S., Liu, R., Xue, H., and Wang, Y., 2014, Food policy approaches to obesity prevention: an international perspective. Current Obesity Reports, 3(2), 171-182.

[13]. Perry, B., and Wang, Y., 2012, Appetite regulation and weight control: the role of gut hormones, Nutrition and Diabetes, 2(1), e26.

[14]. Butt, M.S., Pasha, I., Sultan, M.T., Randhawa, M.A., Saeed, Farhan., and Ahmed, W., 2013, Black pepper and health claims: a comprehensive treatise. Critical Reviews in Food Science and Nutrition, 53(9), 875-886.
[15]. Reshmi, S.K., Sathya, E., and Devi, P.S., 2010, Isolation of piperdine from Piper nigrum and its antiproliferative activity. African Journal of Pharmacy and Pharmacology, 4(8), 562-573.

[16]. Srivastava, A.K., and Singh, V.K., 2017, Biological action of Piper nigrum - the king of spices. European Journal of Biological Research, 7(3), 223-233.

[17]. Tiwari, A., Mahadik, K.R., and Gabhe, S.Y., 2020, Piperine: a comprehensive review of methods of isolation, purification, and biological properties, Medicine in Drug Discovery, 7, 100027.

[18]. Stojanović-Radić, Z., Pejčić, M., Dimitrijević, M., Aleksić, A., Kumar, N.V.A., Salehi, B., Cho, W.C., and SharifiRad, Javad., 2019, Piperine-A major principle of black pepper: a review of its bioactivity and studies, Applied Sciences, 9(20), 4270.

[19]. Dallakyan, S., and Olson, A.J., 2015, Smallmolecule library screening by docking with PyRx, Methods in Molecular Biology, 1263, 243-250.

[20]. Trott, O., and Olson, A.J., 2010, AutoDock Vina: improving the speed and accuracy of docking with a new scoring function, efficient optimization and multithreading, Journal of Computational Chemistry, 31(2), 455-461.

[21]. Hermanto, F.E., Rifa'i, M., and Widodo, 2019, Potential role of glyceollin as antimetastatic agent through transforming growth factor- $\beta$ receptors inhibition signaling pathways: A computational study, AIP Conference Proceedings, 2155, 020035.

[22]. Yan, Y., Tao, H., He, J., and Huang, S-Y., 2020, The HDOCK server for integrated protein-protein docking. Nature Protocols, $15,1829-1852$.

[23]. Chen, D., Oezguen, N., Urvil, P., Ferguson, C., Dann, Sara M., and Savidge, T.C., 2016, Regulation of protein-ligand binding affinity by hydrogen bond pairing, Science Advances, 2(3), e1501240.

[24]. Freitas, R.F. de, and Schapira, M., 2017, A systematic analysis of atomic proteinligand interactions in the PDB, Medicinal Chemistry Communication, 8(10), 19701981.

[25]. Du, Xing., Li, Y., Xia, Y-L., Ai S-M., Liang, J., Sang, P., Ji, X-L., and Liu, S-Q., 2016, Insights into protein-ligand interactions: mechanisms, models, and methods, International Journal of Molecular Sciences, 17(2), 144.

[26]. Asakawa, A., Inui, A., Kaga, T., Katsuura, G., Fujimiya, M., Fujino, M.A., and Kasuga, M., 2003, Antagonism of ghrelin receptor 
reduces food intake and body weight gain in mice. Gut, 52(7), 947-952.

[27]. Mohamed, G.A., Ibrahim, S.R.M., Elkhayat, E.S., El Dine, R.S., 2014, Natural anti-obesity agents, Bulletin of Faculty of Pharmacy, Cairo University, 52(2), 269-284.

[28]. Rezaie, P., Mazidi, M., and Nematy, M., 2015, Ghrelin, food intake, and botanical extracts: a review, Avicenna Journal of Phytomedicine, 5(4), 271-281.

[29]. Zanzer, C.Y., Plaza, M., Dougkas, A., Turner, C., Östman, E., 2018, Black pepperbased beverage induced appetite-suppressing effects without altering postprandial glycaemia, gut and thyroid hormones or gastrointestinal well-being: a randomized crossover study in healthy subjects, Food \& Function, 9(5), 2774-2786.

[30]. Du, Y., Chen, Y., Fu, X., Gu, J., Sun, Y., Zhang, Z., Xu, J., and Qin, L., 2020, Effects of piperine on lipid metabolism in high-fat diet induced obese mice, Journal of Functional Foods, 71, 104011.

[31]. Shah, S.S., Shah, G.B., Singh, S.D., Gohil, P.V., 2011, Effect of piperine in the regulation of obesity-induced dyslipidemia in high-fat diet rats. Indian Journal of Pharmacology, 43(3), 296-299.

[32]. Pastor, M.M., Capua, A.D., Álvarez, C.J.P., Hernández, M.D.D., Barbero, J.J., Casanueva, F.F., and Pazos, Y., 2010, Interaction between ghrelin and the ghrelin receptor (GHS-R1a), a NMR study living cells, Bioorganic \& Medicinal Chemistry, 18, 1583-1590.

[33]. Vortmeier, G., DeLuca, S.H., Heindl, S.E., Chollet, C., Scheidt, H.A., Sickinger, A.G.B., Meiler, J., and Huster, D., 2015, Integrating solid-state NMR and computational modeling to investigate the structure and dynamics of membrane-associated ghrelin, PLOS ONE, 10(3): e0122444. 